\title{
Peroxiredoxin 6 promotes upregulation of the prion protein (PrP) in neuronal cells of prion-infected mice
}

\author{
Wibke Wagner ${ }^{1,3}$, Andreas Reuter ${ }^{1}$, Petra Hüller ${ }^{1,4}$, Johannes Löwer ${ }^{1}$ and Silja Wessler ${ }^{2 *}$
}

\begin{abstract}
Background: It has been widely established that the conversion of the cellular prion protein $\left(\mathrm{PrP}^{\mathrm{C}}\right.$ ) into its abnormal isoform $\left(\mathrm{PrP}^{\mathrm{SC}}\right)$ is responsible for the development of transmissible spongiform encephalopathies (TSEs). However, the knowledge of the detailed molecular mechanisms and direct functional consequences within the cell is rare. In this study, we aimed at the identification of deregulated proteins which might be involved in prion pathogenesis.

Findings: Apolipoprotein E and peroxiredoxin 6 (PRDX6) were identified as upregulated proteins in brains of scrapie-infected mice and cultured neuronal cell lines. Downregulation of PrP gene expression using specific siRNA did not result in a decrease of PRDX6 amounts. Interestingly, selective siRNA targeting PRDX6 or overexpression of PRDX6 controlled PrPC and PrPSC protein amounts in neuronal cells.

Conclusions: Besides its possible function as a novel marker protein in the diagnosis of TSEs, PDRX6 represents an attractive target molecule in putative pharmacological intervention strategies in the future.
\end{abstract}

Keywords: Peroxiredoxin 6, Prion protein, Scrapie

\section{Findings}

Transmissible spongiform encephalopathies (TSEs) are fatal neurodegenerative disorders, which include scrapie in sheep, bovine spongiform encephalopathy (BSE) in cattle, and Creutzfeldt-Jacob disease (CJD) in humans [1]. The molecular hallmark of these disorders is a structural conversion in folding of the normal cellular prion protein $\left(\mathrm{PrP}^{\mathrm{C}}\right)$ into a disease-associated, proteaseresistant isoform $\left(\mathrm{PrP}^{\mathrm{Sc}}\right)$ [2]. Neuropathological characteristics of these diseases include neuronal loss, vacuolar degeneration, astrogliosis and amyloid plaque formation caused by accumulation of $\operatorname{PrP}^{\mathrm{Sc}}$ [3]. However, the mechanism whereby $\operatorname{PrP}^{C} \rightarrow \operatorname{PrP}^{\mathrm{Sc}}$ conversion triggers cellular neurotoxicity and neurodegeneration is not well understood.

$\mathrm{PrP}^{\mathrm{C}}$ is a multifunctional plasma membrane glycosylphosphatidylinositol (GPI)-anchored protein on a wide range of different cell types where it is involved in

\footnotetext{
* Correspondence: silja.wessler@sbg.ac.at

${ }^{2}$ Division of Microbiology, University of Salzburg, Billrothstrasse 11, Salzburg A-5020, Austria

Full list of author information is available at the end of the article
}

adhesion, signal transduction, differentiation, survival or stress protection [4-6]. Obviously, neurodegenerative disorders interconnect several cellular signal transduction pathways to cause oxidative stress in the brain, including increased oxidative damage, impaired mitochondrial function, defects of the proteasome system, the presence of aggregated proteins, and many more [7]. There are a number of cellular antioxidant defenses to convert reactive oxygen species (ROS) into unreactive compounds, e.g. superoxide dismutase (SOD) and the peroxiredoxin (PRDX) family. Proteins of the PRDX family are widely expressed and exhibit crucial protective functions in neurological disorders such as Parkinson's and Alzheimer's diseases [8]. Accordingly, upregulation of PRDX protein was observed in the brain of patients with Parkinson and Alzheimer's disease, and also during experimental prion infection in mice [9-11]. The PRDX family of mammals comprises six isoforms (PRDX1-6), which are classified into the three subgroups typical 2-Cys PRDX (PRDX1-4), atypical 2-Cys PRDX (PRDX5) and 1-Cys PRDX (PRDX6) [12]. Peroxiredoxin 6 is the only 1-Cys member and exhibits bifunctional activities as a

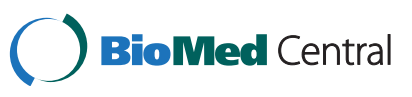


glutathione $(\mathrm{GSH})$ peroxidase and calcium-independent phospholipase $\mathrm{A}_{2}\left(\mathrm{PLA}_{2}\right)$ [13], which might contribute to neurological disorders. In experimental in vivo models for neurological disorders such as Huntington's disease and scrapie, PRDX1 was slightly enhanced [11]. However, the function of distinct PRDX isoforms in prion diseases has not been investigated.

\section{Upregulation of PRDX6 in scrapie-infected brains}

For a better understanding of the proteomic alterations during in vivo prion pathogenesis, $\mathrm{C} 57 \mathrm{Bl} / 6$ mice were intracerebrally inoculated with a $10 \%$ brain homogenate containing the prion strain 139A (Additional file 1). Mice were sacrificed after 40, 80, 120 and 150 days, and brain homogenates were prepared. To confirm prion infection, PrP expression was analyzed by Western blot (Figure 1A). $\operatorname{PrP}^{\mathrm{C}}$ was detected in non-infected brain homogenates in equal amounts 40, 80, 120 and 150 days post infection (p.i.) (Figure 1A, lanes 1, 3, 5, 7), while total PrP of scrapie-infected brain homogenates slightly increased during infection (Figure 1A, lanes 9, 11, 13, $15)$, caused by the accumulation of $\mathrm{PrP}^{\mathrm{Sc}}$ as demonstrated by proteinase $\mathrm{K}(\mathrm{PK})$-digestion (Figure $1 \mathrm{~A}$, lanes $10,12,14,16)$.

To identify differentially regulated proteins in scrapie-infected mice, equal protein amounts of brain homogenates were separated by two-dimensional gel electrophoresis followed by Coomassie blue staining (Figure 1B). Only two up-regulated protein spots were reproducibly detected in four individual mice infected by scrapie, which were then identified by mass spectrometry (Table 1). Apolipoprotein E was found in three out of four investigated samples, while peroxiredoxin 6 (PRDX6) was identified with an overall sequence coverage of $71.4 \%$ in all four tested samples (Table 1). Upregulation of apolipoprotein E has already been described in activated astrocytes in Alzheimer's and prion disease [14] and is considered as one of the

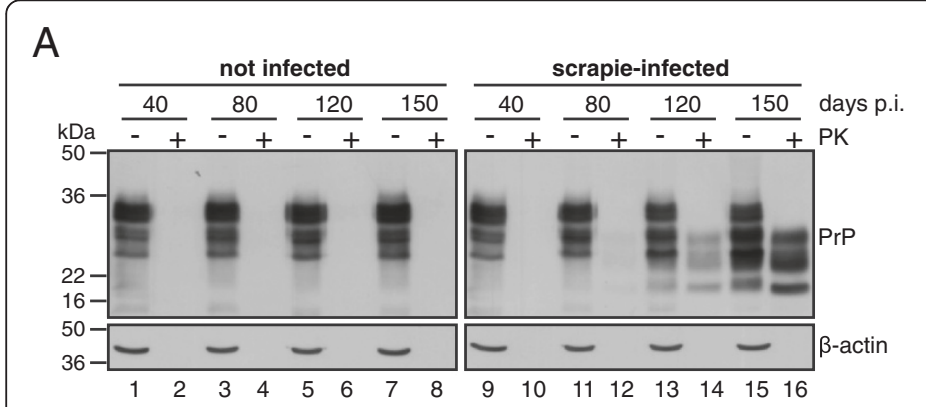

C

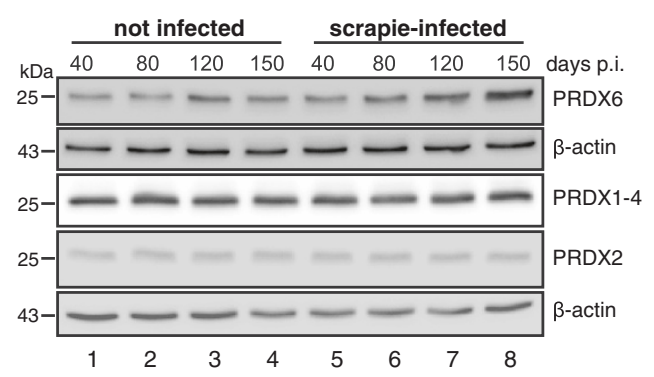

$\mathrm{B}$
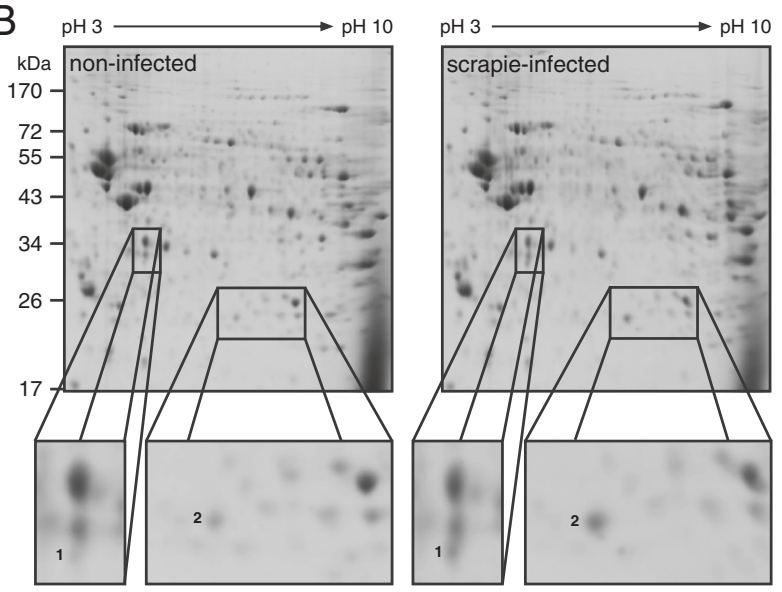

$\mathrm{D}$

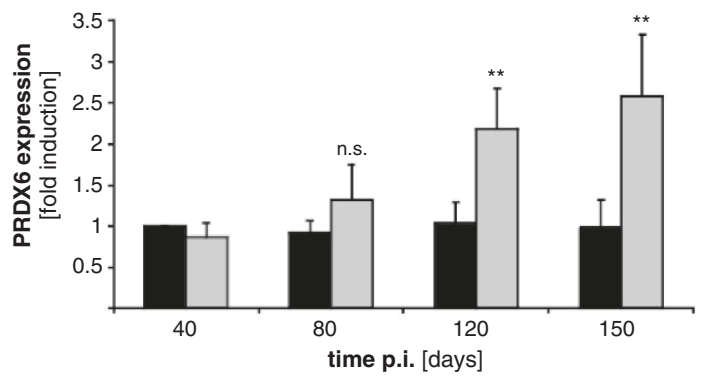

Figure 1 Upregulation of PRDX6 in scrapie-infected mice. (A) C57BI/6 mice were inoculated intracerebrally with PBS (not infected, lanes 1-8) or 10\% brain homogenate of the prion strain 139A (scrapie-infected, lanes 9-16). 40, 80, 120 and 150 days post infection (p.i.) brain homogenates were prepared and incubated with $20 \mathrm{\mu g} / \mathrm{ml}$ proteinase $\mathrm{K}(+, \mathrm{PK})$ or left untreated (-) prior to Western blotting. PrP was detected using the $8 \mathrm{H} 4$ monoclonal antibody showing the typical migration pattern of PrP and PK-resistant PrP ${ }^{\text {res }}$. $\beta$-actin was shown as a loading control. (B) $150 \mu g$ protein of brain homogenates were separated by two-dimensional gel electrophoresis followed by Coomassie blue staining. Enlarged sections indicate differentially expressed proteins (spots 1 and 2) observed in four tested homogenates. (C) $50 \mu \mathrm{g}$ protein of brain homogenates were separated by SDS-PAGE followed by Western blot. PRDX6, PRDX1-4, PRDX2 and $\beta$-actin were detected using specific antibodies. (D) Quantification of protein expression was performed using four independent Western blots detecting PRDX6 (grey bars) and $\beta$-actin (black bars) in brain homogenates of four different mice, respectively. PRDX6 expression was by normalized to $\beta$-actin $(* *, p<0.01$, n.s., non-specific). 
Table 1 Identification of apolipoprotein E and peroxiredoxin 6 by mass spectrometry

\begin{tabular}{|c|c|c|c|c|c|c|}
\hline Spot & Mouse & Acc.nr. & Protein name & Score & Peptide & $\begin{array}{c}\text { Sequence } \\
\text { coverage (\%) }\end{array}$ \\
\hline 1 & 1 & P08226 & Apolipoprotein E OS Mus musculus GN Apoe PE 1 SV 2 & 470.7 & 5 & 19.3 \\
\hline 1 & 3 & P08226 & Apolipoprotein E OS Mus musculus GN Apoe PE 1 SV 2 & 220.7 & 3 & 13.5 \\
\hline 1 & 4 & P08226 & Apolipoprotein E OS Mus musculus GN Apoe PE 1 SV 2 & 215.3 & 4 & 16.4 \\
\hline 2 & 1 & O08709 & Peroxiredoxin 6 OS Mus musculus GN Prd $\times 6$ PE 1 SV 3 & 1023.0 & 10 & 59.4 \\
\hline 2 & 2 & 008709 & Peroxiredoxin 6 OS Mus musculus GN Prd $\times 6$ PE 1 SV 3 & 1176.2 & 11 & 69.6 \\
\hline 2 & 3 & 008709 & Peroxiredoxin 6 OS Mus musculus GN Prd $\times 6$ PE 1 SV 3 & 1737.0 & 11 & 59.8 \\
\hline 2 & 4 & 008709 & Peroxiredoxin 6 OS Mus musculus GN Prd $\times 6$ PE 1 SV 3 & 779.9 & 7 & 33.5 \\
\hline
\end{tabular}

strongest genetic risk factors in Alzheimer disease [15]. Contrastingly, only marginal information is available on the expression of peroxiredoxins in prion disease. Peroxiredoxin protein was preferentially upregulated in astrocytes of prion-infected mouse brains [10], but it remained unknown whether all PRDX family members or a single isoform accumulated. Furthermore, PRDX6 protein expression in astrocytes has already been associated with Alzheimer disease where it might function as an antioxidant enzyme [9] suggesting that PRDX6 might be involved in neurological diseases.

To investigate this in more detail, we followed PRDX6 expression during scrapie infection in mice and compared it with PRDX1-4 amounts by Western blot analyses (Figure 1C). In contrast to non-infected mice (Figure 1C, lane 1-4), the level of PRDX6 steadily increased within 150 days post infection (Figure $1 \mathrm{C}$, lane 5-8). This appears to be highly specific, since amounts of PRDX1-4 or PRDX2 did not change during infection (Figure 1C, lane 5-8). Although we cannot exclude the possibility that PRDX1, 3 or 4 of the 2-Cys PRDX subgroup were slightly regulated, it is obvious that PRDX6 was strongly affected in scrapie-infected mice brains. Quantification of PRDX6 protein expression in brains of four individual mice at each time point after infection indicated that the observed effect was statistically significant and reproducibly observed in scrapie-infected mice (Figure 1D).

\section{Expression of peroxiredoxin 6 in PrP deficient and PrPC expressing neuronal precursor cells}

To investigate PRDX6 expression in more detail, endogenous PRDX6 expression in PrP-deficient and $\mathrm{PrP}^{\mathrm{C}}$-expressing cells was analyzed. The immortalized neuronal precursor cell line $\operatorname{PrP}^{0 / 0} \mathrm{ML}$ derived from $\mathrm{PrP}^{0 / 0}$ ZrchI mice was stably transfected with wild type murine PrP (PrP A109) [16]. Western blots of these cell lines were performed for detection of PrP and PRDX6. As expected, PrP A109 cells expressed $\operatorname{PrP}^{C}$, whereas the $\mathrm{PrP}^{0 / 0} \mathrm{ML}$ cells did not (Figure 2A, upper panel). Corresponding to in vivo studies, PRDX6 expression was increased in PrP A109 cells (Figure 2A, middle panel) while detection of $\beta$-actin indicated equal protein loading (Figure 2A, lower panel). Analyzing mRNA synthesis of prdx6 and prnp, no significant alterations were observed indicating that PRDX6 protein expression was not transcriptionally dependent on PrP (Figure 2B). To clarify whether PrP protein expression led to PRDX6 accumulation, PrP was downregulated using specific siRNAs and the amount of PRDX6 protein was analyzed by Western blotting. Interestingly, successful downregulation of $\operatorname{PrP}$ (Figure 2C, lane 4) did not result in a detectable decrease in PRDX6 protein amount (Figure 2C, lane 4). This finding was further supported by the inhibition of protein translation using cycloheximide. Twentyfour hours incubation of the cells with cycloheximide led to a drastic decrease in PrP expression, while leaving PRDX6 protein amounts unaffected (Figure 2D, lanes 814). Although downregulation of PrP was not complete, these data imply that enhanced PrP expression does not induce PRDX6 expression and that PRXD6 is highly stable in neuronal cells.

\section{PRDX6 induces upregulation of PrP in neuronal cells}

Next, we aimed at the investigation of PRDX6 expression in scrapie-infected neuronal cells. Uninfected $\operatorname{PrP}^{C}$ expressing N2a58\# cells were compared to scrapieinfected N2a58/22L cells. Correspondingly to scrapieinfected mice, an upregulation of PRDX6 was observed in scrapie-infected N2a58/22L cells as shown by Western blot analysis (Figure 3A, upper panel). Signal intensities from four independent experiments were quantified and expressed as fold PRXD6 expression normalized to $\beta$ actin expression (Figure 3A, lower panel). Increased PRXD6 protein amounts were also detected by immunofluorescence analyses underlining enhanced protein occurrence in the cytoplasm, while PrP was mainly localized at the plasma membrane (Figure 3B).

Since PRDX6 was upregulated in $\operatorname{PrP}^{\mathrm{C}}$-expressing and $\mathrm{PrP}^{\mathrm{Sc}}$-infected cells, but not in cells in which $\mathrm{PrP}^{\mathrm{C}}$ expression was downregulated, we tested the hypothesis if PRDX6 is involved in PrP upregulation in turn. In N2a58\# and N2a58/22L cells PRDX6 was successfully downregulated using PRDX6 specific siRNA that did not 


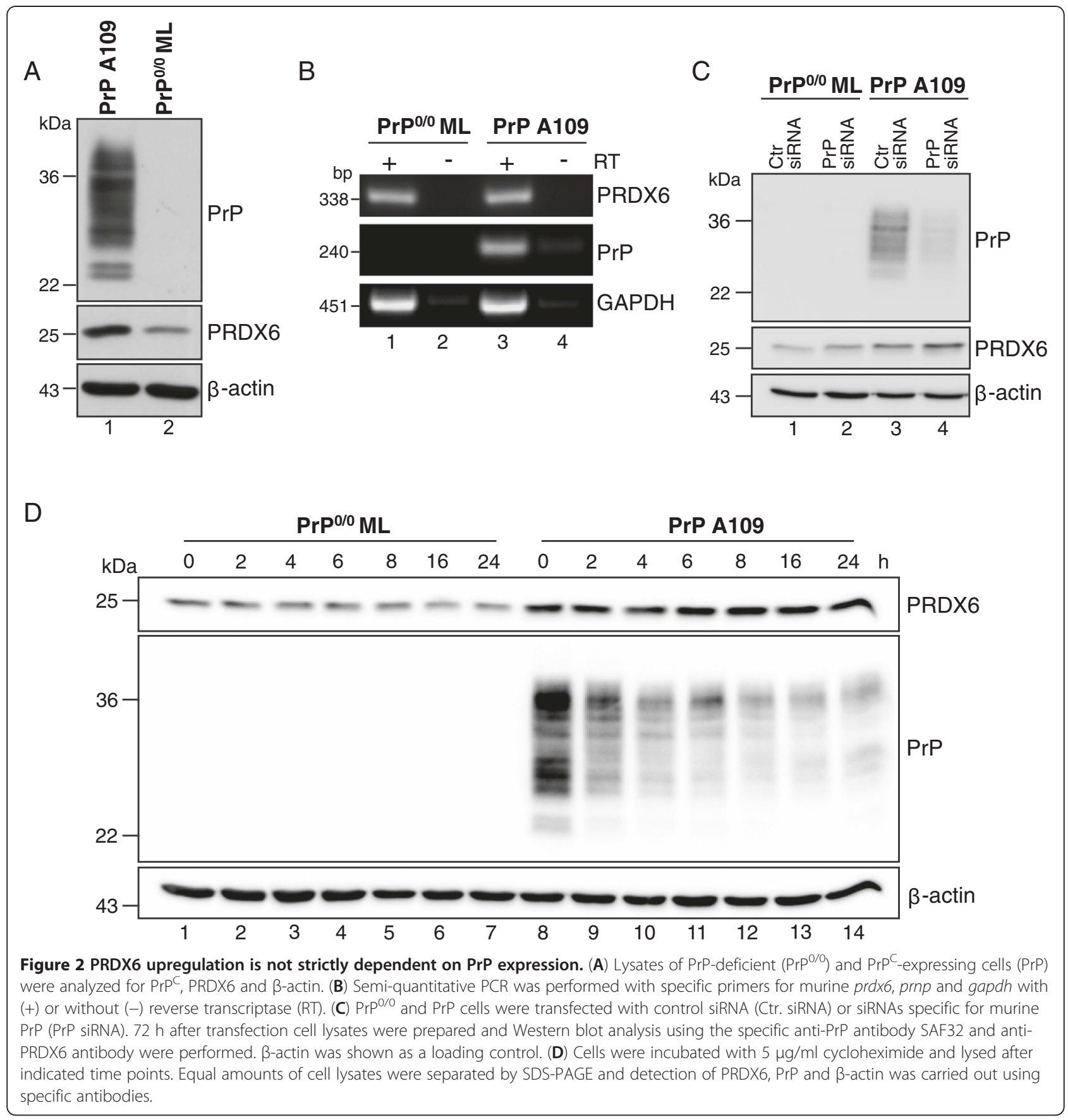

affect PRDX1-4 expression. Interestingly, $\operatorname{PrP}^{C}$ in N2a58\# cells was slightly decreased and PK-resistant $\mathrm{PrP}^{\mathrm{Sc}}$ was strongly reduced in N2a58/22L upon siRNA treatment to inhibit PRXD6 expression (Figure 3C). These data led to the suggestion that there is a functional connection between PrP and PRDX6 expression. Therefore, flag-tagged PRDX6 was overexpressed in $\mathrm{N} 2 \mathrm{a} 58 \#$ and N2a58/22L cells and the amount of $\mathrm{PrP}^{\mathrm{C}}$ and $\operatorname{PrP}^{\mathrm{Sc}}$ was examined. Overexpression of PRDX6-flag had no influence on expression of PRDX1-4 (Figure 3D).
However, PRDX6-flag resulted in a slightly increased amount of $\mathrm{PrP}^{\mathrm{C}}$ in uninfected $\mathrm{N2a} 58 \#$ (Figure 3D, lanes 1-4) and subsequently to an obvious accumulation of PK-sensitive $\operatorname{PrP}^{\mathrm{C}}$ and $\mathrm{PK}$-resistant $\operatorname{PrP}^{\mathrm{Sc}}$ in infected N2a58/22L (Figure 3D, lanes 5-8). PRDX6 exhibits a calcium-independent phospholipase A2 (iPLA $)_{2}$ activity [17]. In N2a58/22L cells, iPLA 2 activity was significantly increased compared to $\mathrm{N} 2 \mathrm{a} 58 \#$ cells. Importantly the difference was completely diminished after downregulation of PRDX6 in both cell lines (Figure 3E). In 


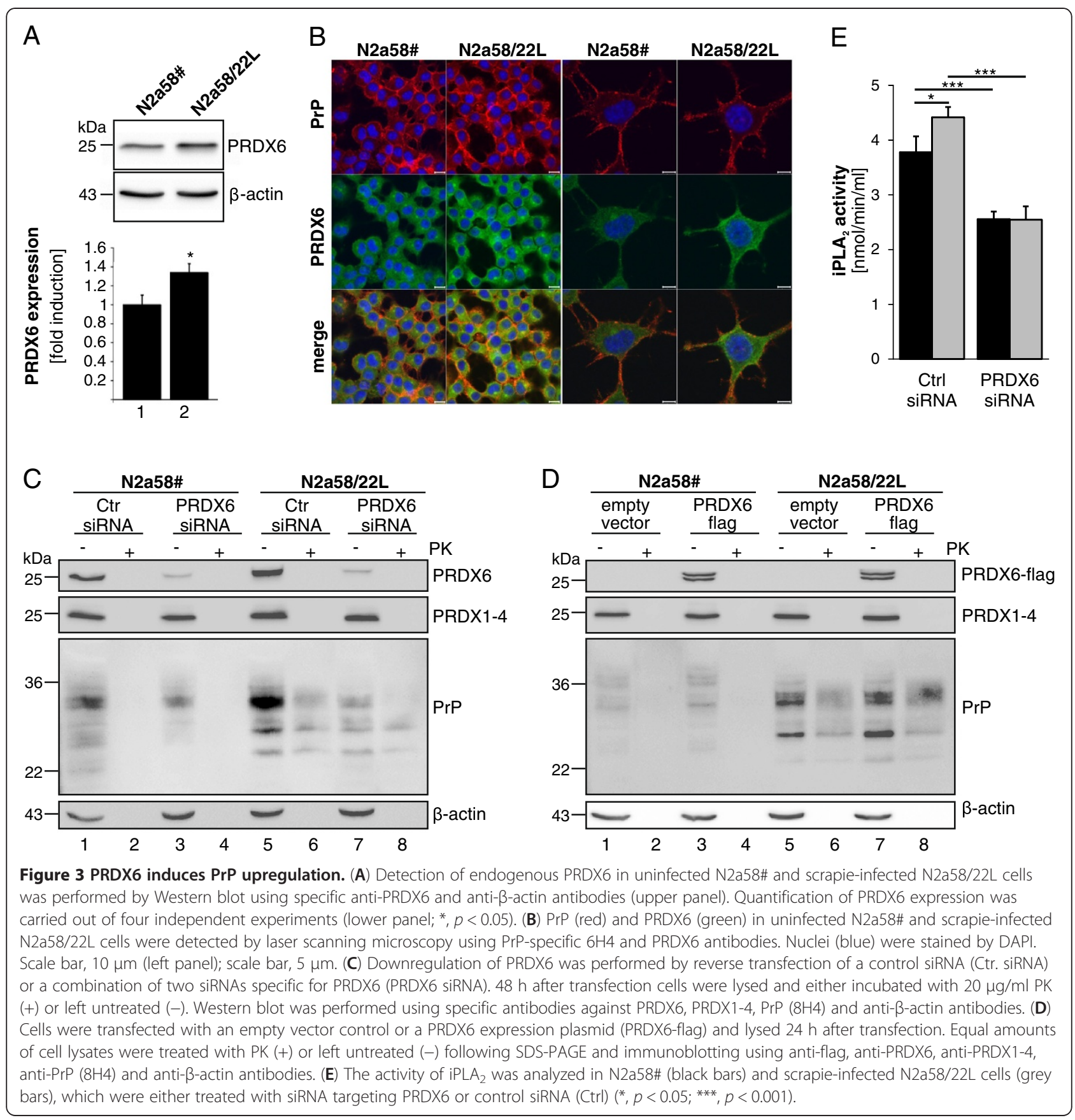

conclusion, these results suggest that the expression level and activity of PRDX6 might be involved in the control of the level of $\operatorname{PrP}^{\mathrm{C}}$ and subsequently $\operatorname{PrP}^{\mathrm{Sc}}$ conversion.

In this study, enhanced amounts of PRDX6 was selectively identified in brains of prion-infected mice and neuronal cell lines concomitant with an increased amount of $\operatorname{PrP}^{\mathrm{C}}$ and consequently of $\operatorname{PrP}^{\mathrm{Sc}}$. This interaction appears very complex, since $\operatorname{PrP}^{\mathrm{C}}$ expression in PrP knock-out cells has also been observed to increase the amount of PRDX6 in turn, but downregulation of PrP did not alter PRDX6 appearance. This effect could be explained by the observation that the PRDX6 protein was more stable than PrP. Hence, the molecular basis for this phenomenon remains unknown, but might indicate a complex "tandem"-regulation of PRDX6 and PrP.

PRDX6 is a moonlighting protein containing peroxidase and $\mathrm{PLA}_{2}$ activities [18]. Specific pharmacological inhibitors for cellular studies are not available, but it is tempting to speculate whether PRDX6 activities are 
involved in PrP regulation. In fact, data are accumulating that $\mathrm{PLA}_{2}$ contributes to prion diseases. Functionally, $\mathrm{PLA}_{2}$ is an important promoter of phospholipid metabolism and cleaves membrane phospholipids to produce arachidonic acid and lysophopholipids as major products [19]. Under normal conditions, arachidonic acid is either re-incorporated into phospholipids, converted to inflammatory mediators in the brain or modulates neuronal functions [20]. It has been demonstrated that $\mathrm{PrP}^{\mathrm{Sc}}$ and the neurotoxic PrP106-126 prion peptide stimulated the $\mathrm{N}$-methyl-D-aspartate (NMDA) receptor [21], which is accompanied by the release of arachidonic acid, suggesting an involvement of $\mathrm{PLA}_{2}$ in prion pathogenesis [22]. This has been supported by neuronal cell culture studies showing that PLA $\mathrm{A}_{2}$ is activated by glycosylphosphatidylinositols (GPIs) isolated from $\operatorname{PrP}^{\mathrm{C}}$ and $\mathrm{PrP}^{\mathrm{Sc}}$ [23]. Interestingly, treatment of CJD using the non-specific $\mathrm{PLA}_{2}$ inhibitor quinacrine resulted in an inhibition of $\operatorname{PrP}^{\mathrm{Sc}}$ formation [24] and reduced toxicity of PrP106-126 [25]. Together with our study, those data point to PRDX6 activities as new important players in the pathogenesis of prion diseases.

\section{Additional file}

Additional file 1: Wagner et al., Cell Communication and Signaling.

\section{Abbreviations}

PRDX6: Peroxiredoxin 6; PrP: Prion protein.

\section{Competing interests}

The authors declare that they have no competing interests.

\section{Authors' contributions}

WW: performed the experiments and wrote the manuscript. AR: conducted and interpreted mass spectrometry analysis. $\mathrm{PH}$ : performed the animal experiments. JL: participated in the design of the study and the interpretation of the results. SW: conceived of the study, and participated in design and coordination and wrote the manuscript. All authors read and approved the final manuscript.

\section{Acknowledgement}

We are grateful to Edgar Holznagel for valuable discussions and Kay-Martin Hanschmann for statistical analysis.

\section{Author details}

'Paul Ehrlich Institute, Paul Ehrlich-Straße 51-59, Langen D-63225, Germany. ${ }^{2}$ Division of Microbiology, University of Salzburg, Billrothstrasse 11, Salzburg A-5020, Austria. ${ }^{3}$ Present address: Department of Biology, Division of Neurosensory systems, Technical University of Darmstadt, Schnittspahnstraße 10, Darmstadt D-64287, Germany. ${ }^{4}$ Present address: Chiltern International GmbH, Norsk-Data-Strasse 1, Bad Homburg v.d.H D-61352, Germany.

Received: 28 July 2012 Accepted: 29 November 2012 Published: 4 December 2012

\section{References}

1. Prusiner SB: Prions. Proc Natl Acad Sci USA 1998, 95:13363-13383.

2. Prusiner SB: Novel proteinaceous infectious particles cause scrapie. Science 1982, 216:136-144.
3. DeArmond SJ, Prusiner SB: Etiology and pathogenesis of prion diseases. Am J Pathol 1995, 146:785-811.

4. Martins VR, Linden R, Prado MA, Walz R, Sakamoto AC, Izquierdo I, Brentani RR: Cellular prion protein: on the road for functions. FEBS Lett 2002, 512:25-28.

5. Westergard L, Christensen HM, Harris DA: The cellular prion protein (PrP (C)): its physiological function and role in disease. Biochim Biophys Acta 2007, 1772:629-644

6. Wagner W, Ajuh P, Lower J, Wessler S: Quantitative phosphoproteomic analysis of prion-infected neuronal cells. Cell Commun Signal 2010, 8:28.

7. Halliwell B: Oxidative stress and neurodegeneration: where are we now? J Neurochem 2006, 97:1634-1658.

8. Zhu H, Santo A, Li Y: The antioxidant enzyme peroxiredoxin and its protective role in neurological disorders. Exp Biol Med (Maywood) 2012, 237:143-149.

9. Power JH, Asad S, Chataway TK, Chegini F, Manavis J, Temlett JA, Jensen PH, Blumbergs PC, Gai WP: Peroxiredoxin 6 in human brain: molecular forms, cellular distribution and association with Alzheimer's disease pathology. Acta Neuropathol 2008, 115:611-622.

10. Kopacek J, Sakaguchi S, Shigematsu K, Nishida N, Atarashi R, Nakaoke R, Moriuchi R, Niwa M, Katamine S: Upregulation of the genes encoding lysosomal hydrolases, a perforin-like protein, and peroxidases in the brains of mice affected with an experimental prion disease. J Virol 2000, 74:411-417.

11. Zabel C, Sagi D, Kaindl AM, Steireif N, Klare Y, Mao L, Peters H, Wacker MA, Kleene R, Klose J: Comparative proteomics in neurodegenerative and non-neurodegenerative diseases suggest nodal point proteins in regulatory networking. J Proteome Res 2006, 5:1948-1958.

12. Rhee SG, Chae HZ, Kim K: Peroxiredoxins: a historical overview and speculative preview of novel mechanisms and emerging concepts in cell signaling. Free Radic Biol Med 2005, 38:1543-1552.

13. Manevich Y, Fisher AB: Peroxiredoxin 6, a 1-Cys peroxiredoxin, functions in antioxidant defense and lung phospholipid metabolism. Free Radic Biol Med 2005, 38:1422-1432

14. Diedrich JF, Minnigan H, Carp RI, Whitaker JN, Race R, Frey W 2nd, Haase AT: Neuropathological changes in scrapie and Alzheimer's disease are associated with increased expression of apolipoprotein $\mathrm{E}$ and cathepsin D in astrocytes. J Virol 1991, 65:4759-4768.

15. Holtzman DM, Herz J, Bu G: Apolipoprotein e and apolipoprotein e receptors: normal biology and roles in Alzheimer disease. Cold Spring Harb Perspect Med 2012, 2:a006312.

16. Barenco MG, Valori CF, Roncoroni C, Loewer J, Montrasio F, Rossi D: Deletion of the amino-terminal domain of the prion protein does not impair prion protein-dependent neuronal differentiation and neuritogenesis. J Neurosci Res 2009, 87:806-819.

17. Kim SY, Jo HY, Kim MH, Cha YY, Choi SW, Shim JH, Kim TJ, Lee KY: H2O2-dependent hyperoxidation of peroxiredoxin $6(\operatorname{Prdx6})$ plays a role in cellular toxicity via up-regulation of iPLA2 activity. J Biol Chem 2008, 283:33563-33568.

18. Fisher $A B$ : Peroxiredoxin 6: a bifunctional enzyme with glutathione peroxidase and phospholipase A(2) activities. Antioxid Redox Signal 2011, 15:831-844.

19. Farooqui $A A$, Ong $W Y$, Horrocks LA: Inhibitors of brain phospholipase $A 2$ activity: their neuropharmacological effects and therapeutic importance for the treatment of neurologic disorders. Pharmacol Rev 2006, 58:591-620.

20. Rapoport SI: In vivo fatty acid incorporation into brain phospholipids in relation to signal transduction and membrane remodeling. Neurochem Res 1999, 24:1403-1415.

21. Perovic S, Pergande G, Ushiijima H, Kelve M, Forrest J, Muller WE: Flupirtine partially prevents neuronal injury induced by prion protein fragment and lead acetate. Neurodegeneration 1995, 4:369-374.

22. Stewart LR, White AR, Jobling MF, Needham BE, Maher F, Thyer J, Beyreuther K, Masters CL, Collins SJ, Cappai R: Involvement of the 5lipoxygenase pathway in the neurotoxicity of the prion peptide PrP106126. J Neurosci Res 2001, 65:565-572.

23. Bate C, Williams A: Role of glycosylphosphatidylinositols in the activation of phospholipase A2 and the neurotoxicity of prions. J Gen Virol 2004 85:3797-3804 
24. Korth C, May BC, Cohen FE, Prusiner SB: Acridine and phenothiazine derivatives as pharmacotherapeutics for prion disease. Proc Natl Acad SCi USA 2001, 98:9836-9841.

25. Turnbull S, Tabner BJ, Brown DR, Allsop D: Quinacrine acts as an antioxidant and reduces the toxicity of the prion peptide PrP106-126. Neuroreport 2003, 14:1743-1745.

doi:10.1186/1478-811X-10-38

Cite this article as: Wagner et al.: Peroxiredoxin 6 promotes upregulation of the prion protein $(\mathrm{PrP})$ in neuronal cells of prion-infected mice. Cell Communication and Signaling 2012 10:38.

\section{Submit your next manuscript to BioMed Central} and take full advantage of:

- Convenient online submission

- Thorough peer review

- No space constraints or color figure charges

- Immediate publication on acceptance

- Inclusion in PubMed, CAS, Scopus and Google Scholar

- Research which is freely available for redistribution 